\title{
Discurso e ensino: diretrizes para conceber novos significados para a escola na contemporaneidade
}

DOI: http://dx.doi.org/10.21165/el.v49i1.2784

\section{Cecilia Maria Aldigueri Goulart ${ }^{1}$}

\section{Resumo}

A escola é o espaço público, coletivo, em que aprendemos sobre o mundo e sobre a ação dos homens no mundo. Espaço de aprendizagem da história do ser humano e de seus conhecimentos e, ao mesmo tempo, de criação de novos conhecimentos e novas possibilidades de vida. O objetivo do ensaio é apresentar diretrizes de uma concepção discursiva de trabalho escolar, pressupondo que todo professor é professor de linguagem. Com base na teoria da enunciação do Círculo de Bakhtin, serão focalizados, ainda que brevemente, dados sobre o trabalho com a oralidade, a leitura e a escrita, na educação infantil, no processo de alfabetização e nas áreas de ensino de História, Física e Ciências, em que alunos estão aprofundando conhecimentos sobre o universo letrado. É o viés discursivo que atravessa e encorpa toda a proposta de trabalho.

Palavras-chave: ensino; concepção discursiva; linguagens sociais; Bakhtin.

1 Universidade Federal Fluminense (UFF), Rio de Janeiro, Rio de Janeiro, Brasil; goulartcecilia@uol.com.br; https://orcid.org/0000-0002-4635-1848. 


\title{
Speech and teaching: guidelines to provide new meanings for school in the present days
}

\begin{abstract}
School is the public, collective space where we learn about the world and the action of men in the world. It's the learning space of the human being history and their knowledge, and at the same time, it's the creation of new knowledge and new life possibilities. The aim of the essay is to present guidelines for a discursive conception of schoolwork, assuming that every teacher is a language teacher. It is also based on the Bakhtin Circle's theory of enunciation and briefly focused on data related to work with orality, reading and writing, early childhood education, the literacy process and the teaching of History, Physics and Sciences, in which students are deepening knowledge about the literate universe. It is the discursive view that goes through and embodies the whole work proposal.
\end{abstract}

Keywords: teaching; discursive conception; social languages; Bakhtin.

A reflexão sobre a relação entre discurso e ensino me levou a recuperar o caminho que venho percorrendo como pesquisadora formada na área de Letras, com os pés na Educação. Não trago novidades, propriamente. O novo é observar uma trajetória que retoma aspectos de minha formação como pesquisadora e orientadora de estudos, para considerar a relação discurso-ensino. As diretrizes para conceber novos significados para a escola na contemporaneidade vêm deste caminhar. A escola é o espaço em que aprendemos sobre o mundo e sobre a ação dos homens no mundo. Espaço de vida pública, coletiva, em que cada integrante se recria, conhecendo e renovando possibilidades e limites. Cada um se universaliza e se individualiza, se identifica e se diferencia. A escola é lugar de ensino e aprendizagem, espaço de saber sobre a história do ser humano e seus conhecimentos e, ao mesmo tempo, de produção de novos conhecimentos e novas possibilidades de vida. Preenchida por palavras, enunciados dos sujeitos que a habitam, constitui-se em arena em que processos de ensino e aprendizagem acontecem.

O interesse pelo conceito de discurso me conduziu à temática da aquisição da linguagem. Para ir além, o interesse brotou vivendo a experiência profissional na rede pública municipal do Rio de Janeiro, como professora alfabetizadora, professora de língua portuguesa e de língua inglesa. A pesquisa propriamente se construiu na perspectiva de investigar aspectos do processo inicial de aprendizagem da produção de textos escritos, no mestrado (PACHECO, 1992), expandindo-a no curso de doutorado (PACHECO, 1997), ambos na PUC-Rio. Uma forte ligação e o compromisso com a escola pública guiaram as decisões.

Estávamos no final da década de 1980. No contexto dos estudos sobre alfabetização e ensino de língua portuguesa, a leitura dominava a cena. Historicamente considerada o carro-chefe do trabalho escolar, a leitura protagoniza investigações sob muitas 
perspectivas: concepções de leitura, estratégias de leitura, formação do leitor, história de leitores e leituras, metodologias de ensino de leitura, entre muitas outras.

Não posso deixar de mencionar outros aspectos condicionantes do período que vivíamos no país: tempo recente de abertura política após mais de 20 anos de ditadura militar. A necessidade de recuperar tempos e vozes calados. E repensar caminhos democratizadores para a sociedade, acreditando que a sociedade poderia ser diferente, que direitos e deveres poderiam ser discutidos e garantidos, no contexto do diálogo com associações de moradores e outros movimentos sociais. E, na direção apontada, a possibilidade de questionar a realidade educacional injusta e desumana que deixava de fora dos processos de aprendizagem um percentual enorme de crianças e jovens brasileiros, como ainda acontece, de modo menos acentuado.

Os estudos e as reflexões que eu vinha realizando sobre modos como o ensino da escrita acontecem na escola me encaminhavam a considerar nas práticas de alfabetização, para além da leitura, a produção de textos escritos, sem perder de vista o contexto da fala que, de um modo geral, banha a criação de textos escritos na escola. Pressupomos que a fala e a escrita tenham relevância pela oportunidade de cada um dizer a sua própria palavra, externar o que sabe e não sabe, o que conhece, como pensa. Essa produção movimenta nosso universo de sentidos, nosso discurso interior, nossa consciência, de forma diferente do movimento causado pelo ato de ler, em que também produzimos sentidos para compreender, para interpretar o lido. As dimensões do processo de ensinoaprendizagem são assim pensadas dialeticamente. O processo de produção de textos escritos é o foco das investigações que realizo até os dias atuais.

Os resultados das primeiras pesquisas (PACHECO, 1992, 1997) indicam que o tipo de trabalho pedagógico realizado nas salas de aula tem influência sobre o desempenho das crianças. Mostram que modos de ensinar e modos de aprender estão intrinsecamente relacionados não somente no plano da relação com os conteúdos, mas também no plano da relação com os modos como os alunos são concebidos nos espaços da sala de aula.

De acordo com nossas investigações, práticas pedagógicas centradas na vida das crianças e em seus conhecimentos apresentam resultados que vão muito além do que é característico, trivial, encontrar em classes de alfabetização. Em que direção? Na direção da ampliação do conhecimento de mundo, ultrapassando a perspectiva de aprender o sistema alfabético de escrita - a relação entre fonemas e grafemas, as vogais, as consoantes, as famílias silábicas, por exemplo. A escrita é elaborada heuristicamente no movimento de ampliação do conhecimento de mundo, do jeito como as crianças a entendem, a concebem primeiramente, e, na caminhada, cada vez mais se aproximando das textualidades e das convenções ortográficas mobilizadas nos gêneros do discurso utilizados. A compreensão de que a escrita não é um código, embora guarde uma dimensão de codificação, se explicita com clareza na investigação. O ponto de partida 
pedagógico da sala de aula investigada em 1997 especialmente, porque acompanhada durante dois anos letivos, é a intensa circulação de textos escritos em rodas e conversas, atravessada por intenso movimento de fala.

O fato de as crianças terem a oportunidade de começar a escrever do modo como podem, objetificando aos poucos a linguagem, como condição para analisá-la, está diretamente relacionado aos resultados encontrados. As crianças foram apreendendo o valor simbólico do sistema alfabético, ao mesmo tempo em que se apropriavam de outra forma de entender e apresentar a realidade. E conversavam sobre o tema e suas nuances.

As escritas a que as crianças tiveram acesso, nascidas no interior de práticas culturais socialmente marcadas, foram matrizes de soluções para a elaboração de seus próprios textos, no decorrer do processo de aprendizagem. As escritas foram estruturantes da referida produção, ao se estabelecerem como indícios para a construção de estratégias pelos sujeitos. Podemos dizer que os textos das crianças se organizaram no diálogo com textos de seus interlocutores: orais e escritos, da professora e de colegas, e mesmo os textos de suas vidas.

O processo de alfabetização envolve conhecimento fundamental para o processo de escolarização, pela abertura para a inserção dos sujeitos no valorizado e vasto mundo social letrado. Envolve outros aspectos e conhecimentos também: novas formas de existência e participação política, ligadas à compreensão de múltiplas linguagens sociais e gêneros discursivos e à possibilidade de transformação dessas linguagens e gêneros e de criação de novos enunciados, novos textos.

O enunciado, de acordo com Bakhtin, é o objeto dos estudos da linguagem: de significação e da cultura, social e histórico, um tecido organizado e estruturado. Deve ser analisado nas relações internas e externas: sua organização, a interação verbal, o contexto as condições de produção. Nele habitam muitas vozes sociais, que se completam, polemizam, respondem umas às outras.

O princípio dialógico e a categoria linguagens sociais têm sido aspectos chave para considerar como argumentativo o movimento enunciativo do discurso de diferentes áreas de conhecimento, de acordo com nossos estudos (GOULART, 2007, 2009, 2010, 2011). Os discursos se constituem orientados externamente, povoados de intenções e acentos de outros nos discursos, por isso temos assumido que enunciar, nesta concepção de linguagem, é argumentar. A argumentatividade do discurso seria inerente ao princípio dialógico, já que todo enunciado é produzido na direção do outro, no movimento da interminável cadeia de enunciações. Enunciando, estamos agindo sobre o outro, argumentando, o que significa ir além de compreender e responder a enunciados. 
O diálogo é considerado como movimento e método de constituição dos discursos que historicamente vêm-se organizando como linguagens sociais. As linguagens sociais são entendidas como modos de estruturação dos saberes de diferentes campos do conhecimento: "pontos de vista específicos sobre o mundo, formas da sua interpretação verbal, perspectivas específicas objetais, semânticas e axiológicas" (BAKHTIN, 1998, p. 98). Carregadas de conteúdos que as especificam, vão muito além do vocabulário; são formas de orientação intencional de interpretação, com direções definidas, impregnamse de apreciações concretas, ao unirem-se a objetos de estudo, áreas de conhecimento e gêneros. Nas linguagens há distinções metodológicas, já que se orientam por princípios básicos de seleção e constituição diversos.

As linguagens sociais são consideradas por nós como argumentações por orientarem projetos enunciativos que ordenam os conhecimentos de determinadas maneiras, elaborados na convergência e divergência de diferentes pontos de vista e visões de mundo, espacial e temporalmente condicionadas. Orientam-se por valores e têm seus sentidos validados por acentos apreciativos, em geral, transmitidas como palavras de autoridade, pelo apagamento que se efetua dos embates e dos processos que as condicionam a se estabilizarem de determinadas formas.

Nesse sentido, o ensino dos conteúdos das áreas, sobretudo em perspectiva histórica, ganha peso, na medida em que pode trazer à tona os embates e os processos mencionados, e revelar diferentes modos de argumentação na construção de conceitos, fatos, fenômenos e outros, compondo registros das diversas áreas.

O problema não está na existência de certos estilos de linguagem, dialetos sociais, etc., existência essa estabelecida por meio de critérios meramente linguísticos; o problema está em saber sob que ângulo dialógico eles confrontam ou se opõem na obra. Mas é precisamente esse ângulo dialógico que não pode ser estabelecido por meio de critérios genuinamente linguísticos, porque as relações dialógicas, embora pertençam ao campo do discurso, não pertencem a um campo puramente linguístico do seu estudo. (BAKHTIN, 2005, p. 182, grifos do autor).

Impossível conceber relações dialógicas sem relações lógicas e concreto-semânticas, embora aquelas não sejam redutíveis a estas, por terem especificidade própria, conforme afirma Bakhtin (2005). Nesta contraposição se sustenta a distinção entre a argumentação na perspectiva da língua e na perspectiva do discurso. O caráter dialógico organiza a argumentação no discurso quando sua organização é concebida cronotopicamente: temporalidades e espacialidades atravessam a produção de linguagem.

De acordo com Bakhtin (2005), o enunciado está voltado para o seu objeto, mas também para o discurso do outro acerca desse objeto. E no enunciado tanto as forças centrífugas quanto as forças centrípetas são postas em ação: forças da criação e forças da conservação do sistema. Áreas de conhecimento como História, Geografia, 
Matemática, Física, Biologia, entre tantas outras, se formam como diferentes linguagens sociais, encorpando-se, fazendo-se conhecer e reconhecer por diferentes construções composicionais que incorporam seus conhecimentos, conformando nossos modos de ver a realidade, de variadas perspectivas. "[...] nossa transformação ideológica é justamente um conflito tenso no nosso interior pela supremacia dos diferentes pontos de vista verbais e ideológicos, aproximações, tendências, avaliações". (BAKHTIN, 1998, p. 146).

Que tipo de experiência os alunos vivenciam para aprender? O que deve pautar a criação de metodologias de ensino pelos professores? Se enunciando, estamos agindo na direção do outro, argumentando em determinadas direções, como trabalhar considerando os conhecimentos que os alunos já têm, levando-os a outras dimensões do saber?

Cena de sala de aula $1^{2}$

- Aula de Física, $3^{\circ}$ ano do Ensino Médio

O cobertor

Domingo passado Zeca resolveu fazer um churrasco e comprou uma pedra de gelo para gelar as bebidas. Enquanto Zé, primo do Zeca, arrumava as garrafas no isopor, Zeca enrolou a pedra de gelo em um cobertor para que não derretesse. Diga, justificando, se o procedimento de Zeca está fisicamente correto ou não.

A (Aluno)1: quando tá frio, você usa o cobertor, ele aquece. Quando tá quente, você usa o cobertor, ele aquece. (falando de forma cadenciada)

A7: quando tá... Se você colocar...

A6: é porque você que tá produzindo calor.

A7: é porque tu tá liberando e o cobertor tá deixando calor ali.

A8: é que nem a lã...

A8: professor, minha resposta tá péssima.

A2: o gelo não produz calor.

2 Dados da dissertação de Charret (2009), coorientada por mim; alunos do $3^{\circ}$ ano do Ensino Médio. 
A8: a resposta... O meu problema é português.

P(Professora): por quê?

A8: porque eu tô ficando redundante, eu tô falando: energia, energia, energia. Calor, calor, calor. Aí tá ficando ruim. Eu tô há meia hora aqui.

P (baixinho): energia, energia, energia. Calor, calor, calor.

A9: É Física, não é português.

P: Mas a gente precisa dele.

A17: onde que ele deixou a pedra [de gelo] enrolada no cobertor? (Retornando à questão que inicia os turnos de fala)

P: esperando o isopor ficar pronto.

A71: Sim. Mas, dependendo do local onde ele deixou... Porque se ele deixar no Sol, o cobertor vai aquecer e derreter o gelo. Mas, se não, não vai fazer nada disso.

P: O cobertor aquece?

A17: Não. Mas, se tiver com a luz solar em cima dele, aquece.

P: Então, é melhor você colocar na sombra.

A17: Aí ele vai ficar na sombra, só que não aqueça, vai manter.

A17: Não! Você me deixa confusa.

A71: Porque toda a minha vida, eu usei o cobertor para me aquecer. Hoje em dia, eu não uso mais para me aquecer, eu uso para reter o calor. Isso não é legal.

A reflexão do aluno ao ser provocado a pensar (ao ser ensinado) sobre a situação proposta pela professora, é traduzida com todas as letras como uma experiência de vida, uma experiência linguística. Não há como apartá-las. Ou há? Um novo modo de conceber uma situação de vida que se choca com seu conhecimento de mundo, uma nova linguagem social. A dificuldade de digerir a palavra de autoridade da Ciência se evidencia. O ângulo dialógico de confronto está explícito: como aceitar o que parece ser um paradoxo? Todo professor é professor de linguagem.

Diogo, um aluno da turma cuja conversa na aula de Física foi parcialmente exposta anteriormente, elaborou o texto abaixo, em aula da mesma disciplina. O texto é resultado de uma proposta de que os alunos escrevessem sobre sua relação com a disciplina Física, considerando a experiência com a disciplina ao longo dos três anos do Ensino Médio. Embora longo, vale a pena lê-lo e refletir sobre sua organização. 
"A física está em todos os lugares" dizem os físicos e outros que se enveredam por esses caminhos. Apesar de não estar entre eles devo me confessar simpatizante. Sendo assim venho mostrar que as leis da mais notável das ciências se aplicam a ocasiões bem distantes de sua alçada.

O ano é 1905, o local: Rússia. Uma partícula A (vamos chamá-la de Tzar Nicolau II) segue sua vida em movimento uniforme, dia nababesco após dia nababesco, feliz da vida ganhando um burro dum dinheiro para não fazer nada, o que nos leva a partícula B (a qual chamaremos de Povo). O povo também seguia em movimento uniforme, mas em condições ligeiramente diferentes, enquanto o Tzar ganhava muito e trabalhava pouco, o povo trabalhava muito e não ganhava nada.

E assim se deu até que por um repentino desejo de nossa majestade Nicolau II de ganhar mais e continuar sem trabalhar, o povo foi obrigado a comprar uma guerra com os japoneses e, pra melhorar sua situação, foi massacrado cruelmente. Para muitos isso seria o suficiente para pegar a aceleração nula do povo e aumentá-la absurdamente, mas a inércia as vezes resiste a grandes forças, de forma que a única coisa feita pelos prejudicados foi aparecer a porta do Tzar pedindo ajuda.

É também digno de nota o fato de que o Tzar havia sido criado basicamente dentro do palácio e, ao ver uma cambada de camponeses fedidos e desdentados, fez o que o seu senso de asseio achou melhor, abriu fogo contra o povo. A reação contra esse absurdo veio em forma de lágrimas e velas.

O caro leitor deve estar se perguntando qual a relação que uma partícula inerte mesmo exposta as mais absurdas forças tem com as leis básicas da mecânica. Peço apenas um pouco mais de paciência, pois em 1914 o povo foi novamente convocado a guerra, mas dessa vez a situação seria um pouco pior.

A primeira grande guerra matou russos aos milhões e foi (finamente!) o estopim para a revolta do tão esculachado povo.

Nosso querido Tzar teve a cabeça provisoriamente separada do pescoço e nem seu cachorro escapou.

Moral da história? Um corpo continua inerte a não ser que alguma força externa exerça influência sobre ele, ainda que as vezes essa força deva ser bem grande.

Como podemos ler o texto de Diogo? Texto de História? De Física? Uma redação para a aula de Língua Portuguesa? Quantos conhecimentos articulados! Quantas vozes, 
tempos, espaços organizando a resposta responsável de Diogo à proposta da professora. Fiquemos com essas questões, por enquanto.

A situação do analfabetismo no Brasil se mostra ainda preocupante, especialmente quando ouvimos depoimentos de professores dos anos finais do Ensino Fundamental e do Ensino Médio sobre a precária compreensão que muitos alunos têm da leitura e da escrita de textos. Os dados do INAF 2018 (Indicador Nacional de Analfabetismo Funcional) nos informam que 34\% da população de 15 a 64 anos investigada, com escolaridade declarada dos anos finais do Ensino Fundamental, se situam nos níveis de alfabetismo de Analfabeto e Rudimentar, classificados como analfabetos funcionais. Uma parcela de 13\% do grupo, com Ensino Médio declarado, também é classificada do mesmo modo, além de $4 \%$ daqueles que declaram ter Ensino Superior ${ }^{3}$. Desalentadores índices. O que acontece? Seriam estas questões relacionadas somente ao processo de alfabetização? Ou estariam relacionadas a modos de falar, ler e escrever na escola? Ou ao modo compartimentado de trabalhar com disciplinas escolares? Dificuldade de alfabetizar plenamente as pessoas?

Cerca de $50 \%$ da população investigada, portanto, que se esperava plenamente alfabetizada, conforme a expectativa de documentos e propostas educacionais nacionais, e a expectativa de todos, de um modo geral, ou são considerados analfabetos ou apresentam nível rudimentar de alfabetismo. No nível rudimentar, espera-se que a pessoa localize uma ou mais informações explícitas, expressas de forma literal, em textos muito simples (calendários, tabelas simples, cartazes informativos) compostos de sentenças ou palavras que exploram situações familiares do cotidiano doméstico e reconhece sinais de pontuação (vírgula, exclamação, interrogação, etc.) pelo nome ou função (INAF, 2018, p. 21). Nesse nível, não há um mergulho no sentido dos textos, mesmo de textos considerados simples, conhecidos superficialmente.

Como dar conta de ensinar e não perder a riqueza da complexidade do mundo, das pessoas, de suas histórias e produções? Voltamos à década de 1990. Conhecer o trabalho do Professor Carlos Franchi teve um sentido de liberdade para revisitar a língua, seu estudo e seu ensino. Primeiramente, conheci o professor por meio do trabalho fundamental de João Wanderley Geraldi, depois por Franchi, ele mesmo. Assisti inclusive a uma mesa redonda na Unicamp em que o tema era Aquisição da linguagem e Franchi focalizou justamente o processo de produção de textos. Naquela mesa, Franchi discorreu sobre determinações e indeterminações da linguagem, que me levaram a voar longe. Concluiu a fala lendo uma pequena poesia de aluno, cujo último verso era: "Eu me mim comigo". Jamais esqueci da fala do professor e da poesia que carrego vida acadêmica afora, relatando a passagem para alunos em aulas. Também não me é possível esquecer

3 Indicador Nacional de Alfabetismo Funcional - INAF. Para informações completas sobre a pesquisa, consultar o Relatório INAF Brasil 2018. Resultados preliminares em: https://bit.ly/3cvNiTs. 
da pessoa do professor Franchi: calmo, instigante, delicado e acolhedor das questões suscitadas.

Retornei de Campinas para o Rio "eu-me-mim-comigo": muitas questões, muitas fotocópias de livros eartigos cotejados na biblioteca do Instituto de Estudos da LinguagemIEL/Unicamp. E animada para continuar a estudar, com a descoberta de novos caminhos. Nessa época já havia comprado o livro de Ana Luiza Bustamante Smolka, A criança na fase inicial da escrita: alfabetização em perspectiva discursiva (SMOLKA, 1988). Por dificuldades de compatibilização com autores que vinha lendo, somente após a defesa de tese pude conquistar espaço para esta e outras leituras, inclusive de M. Bakhtin, que havia lido um pouco em disciplina eletiva no Programa de Pós-graduação em Educação da PUC-Rio, à época do curso de doutorado, mas que não entrava no Programa de Pós-graduação em Letras.

A teoria da enunciação de Bakhtin se torna o suporte teórico principal de meus estudos a partir do final dos anos 1990. A língua compreendida na perspectiva do princípio dialógico e do conceito de enunciado do Círculo de Bakhtin ganha densidade com a leitura dos livros Marxismo e filosofia da linguagem, Estética da criação verbal e, posteriormente, Questões de estética e literatura. O viés filosófico, histórico, antropológico e sociológico do estudo faz aparecer o sujeito concreto, vivo, criador, humano. E nos provoca a entender os processos cognitivos de forma integral e integrada ao processo de aprender a dar sentido ao mundo, a significá-lo, vivendo no mundo, interagindo semioticamente. Aprender a língua para viver e sobreviver, sendo reconhecido e afirmado pelo outro, única possibilidade de constituição de subjetividade - na teia da intersubjetividade, interativamente.

Do ponto de vista pedagógico, conceber os sujeitos na dimensão de suas vidas, de seus valores, de suas histórias, no horizonte da constituição em linguagem, começou a fazer toda diferença. Foi relevante entender que com a linguagem nos humanizamos e criamos redes de sentido na grande rede social, heterogeneamente movimentada por condicionantes axiológicos. A perspectiva da criação assume papel de destaque, considerando que Bakhtin (2019, p. 69) "[...] se vale da escritura literária, da arte verbal, para a construção de uma semiótica e de uma filosofia da linguagem que, dialogicamente orientadas, estejam à altura de analisar os signos de que é feita a própria imagem para cada um, na tessitura entre eu-para-mim, eu-para-o-outro, outro-para-si".

Da literatura, então, veio o material para suas reflexões filosóficas, perspectiva sob a qual pode imaginar a fundante relação eu-outro, a exotopicamente dar existência a uma multiplicidade de vidas e experiências sob o signo da alteridade. Na direção apontada, o diálogo é um limite do horizonte do sujeito, um obstáculo à sua definição, não é uma prerrogativa do sujeito individual, portanto. Deste modo, "o diálogo não pode ser reduzido à troca formal de turnos de falas entre interlocutores [...]", importante destacar (BAKHTIN, 2019, p. 74). 
Possenti (2001) afirma que, para dizer que um texto é bom, não pode ser avaliado apenas com base em categorias da textualidade, como abordam as teorias do texto. O autor acredita que um bom texto só pode ser avaliado em termos discursivos: "[...] a questão da qualidade do texto passa necessariamente pela questão da subjetividade e de sua inserção num quadro histórico - ou seja, num discurso - que lhe dê sentido. [...] trata-se tanto de singularidade quanto de tomada de posição" (POSSENTI, 2001, p.110). A subjetividade é um elemento inseparável da natureza linguística dos enunciados.

A crítica de Possenti se manifesta contra as concepções que consideram subjetividade como criatividade, beleza ou, ainda, aquela em que se destaca o diferente. A subjetividade se destaca porque as marcas da história de vida, do pertencimento ao grupo social são produtos da ordem do como os sujeitos significam as situações de interlocução, de acordo com o autor.

Dados anedóticos têm sido fundamentais para refletirmos sobre aspectos dos processos de ensino e de aprendizagem das crianças. Quando, em uma sala de atividades de Educação Infantil, uma criança de 3 anos olha uma imagem no livro e diz "O Saci só tem uma perna porque é pequeno, a outra ainda vai crescer", busca, dentro da lógica de seu pensamento, um modo de explicar a falta da perna do Saci. Não importa que a explicação não encontre eco na experiência com seu próprio corpo e com o corpo das demais pessoas, em que as pernas crescem simultaneamente.

Outro dado vem do relato da professora Marlene Carvalho/UFRJ, que havia participado de pequena reunião em junho de 2015, na UERJ, com a pesquisadora argentina Emilia Ferreiro, de passagem pelo Rio de Janeiro. Emilia Ferreiro contou que um menininho foi à missa com a mãe e na saída disse já saber o que queria dizer "Amém".

- O que é? - perguntou a mãe.

- Quer dizer ENTER. - respondeu o garoto.

Pessoas públicas, do mesmo modo, relatam experiências infantis em que lutavam com dificuldades de compreender, mais do que o sentido das palavras, formas de ver o mundo. Nelson Rodrigues (1997) lembra que, quando criança, lia Zola e não sabia o que era nádega. 0 autor falava em nádega e ele, Nelson, ficava na dúvida se nádega era na frente ou atrás.

Poeticamente, se põem em disputa versões para coisas do mundo, em visões particulares, que acabam por gerar outros mundos possíveis, aliviando muitas vezes as opressões do mundo oficial. Neruda (2008, p. 98) expressa a inquietação humana sobre modos como são entendidas coisas da natureza. 
Se todos os rios são doces, de onde o mar tira o sal?

Como sabem as estações do ano que devem trocar de camisa?

Por que são tão lentas no inverno e tão agitadas depois?

E como as raízes sabem que devem alçar-se até a luz e saudar o ar com tantas flores e cores?

É sempre a mesma primavera que repete seu papel?

E o outono?... ele chega legalmente ou é uma estação clandestina?

Bakhtin destaca que é no movimento da vida da cultura que os fenômenos deixam de ser meros fatos, adquirem sentido, singularidade criativa. A orientação dialógica do discurso é a base para a construção de relações interativas, no movimento de linguagens sociais de diferentes naturezas. A cultura, por meio da arte, da ciência, da filosofia etc., pode ter papel especial, como já vêm apontando professores.

A tradição de trabalho com a língua na escola tem a marca do estruturalismo no estudo de organizações fônicas, morfológicas, e, mais limitadamente, sintáticas. O foco é no significante, segmentado até obter elementos mínimos (fones, fonemas, traços fônicos, morfemas, lexemas, classes sintáticas), em termos de suas propriedades combinatórias e distribucionais, como ressalta Salomão (2009). Nessa busca de precisão se exclui o sujeito: uma língua sem falantes, sem alma, sem vida.

De acordo com Bakhtin (1988, p. 108),

Os indivíduos não recebem a língua pronta para ser usada; eles penetram na corrente de comunicação verbal; ou melhor, somente quando mergulham nessa corrente é que sua consciência desperta e começa a operar. [...] Os sujeitos não 'adquirem' sua língua materna; é nela e por meio dela que ocorre o primeiro despertar da consciência.

O conceito de enunciado articula a memória e a história como elementos ativos na produção e na atribuição de sentidos (SANTOS, 2015). Mesmo que a memória e a história não estejam explicitadas na situação imediata, num enunciado ou numa cena de interação social, caracterizam-se como elementos discursivos que atravessam o enunciado concreto, informa ainda a autora. Os enunciados associam-se a uma dimensão avaliativa e expressam uma posição social valorativa.

As línguas não são material homogêneo, são material flexível. A gramática é entendida como o conjunto de processos e operações pelos quais o homem reflete e reproduz suas experiências no mundo e com os outros, podendo inclusive viajar, por meio deles a universos inimagináveis: "um sistema aberto a uma multiplicidade de escolhas, que permite não somente ajustar as expressões aos propósitos e intenções comunicativas 
do locutor, mas ainda marcar cada texto com a marca de um estilo, não menos expressivo por ser estilo" (FRANCHI, 1987, p. 43).

A experiência de ensinar e aprender pode ser dialogada, interativa, criativa. Que sujeitos desejamos formar para que sociedade? O pensamento crítico se desenvolve no movimento alteritário, no movimento com o outro. Nesse movimento reconhecemos diferenças, novas formas de ser e viver. A sala de aula precisa se abrir para a comunidade que recebe: ouvindo-a, principalmente. Conhecendo-a. Trabalhando com ela, interagindo com ela. Valorizar as relações entre os diferentes sujeitos e os sentidos que produzem. As interações estão em permanente construção, movimento em que tudo se implica mutuamente e os elementos em ação interferem uns sobre os outros (MACHADO, 2010). As dimensões ética e estética entranham o movimento de construção de sujeitos, sempre inacabados, e de relações dialógicas entre eles em que a alteridade se constitui como coordenada principal da formação de sujeitos que interagem responsavelmente. O conceito de responsabilidade/respondibilidade diz respeito ao caráter da resposta em sua versão questionadora, inventiva, motivadora de outra(s) pergunta(s), processada pelo diálogo em acontecimento ético. A compreensão da constituição do eu com e pelo outro é tratada pelo autor como condição da existência humana, que se manifesta desde o início da vida da criança.

Para ilustrar a concepção de linguagem social e seus modos de formação e ação na sociedade, apresentamos abaixo uma sequência de enunciados que vão crescendo em complexidade linguístico-discursiva, à medida que um processo de transformação vai acontecendo, da matéria bruta até um produto refinado. Numa ponta, um enunciado com a marca da coloquialidade do cotidiano e, na outra, um enunciado cientificamente marcado pela linguagem social da Química. O material foi retirado da internet ${ }^{4}$.

1- Rapadura é doce, mas não é mole, não.

2- Açúcar mascavo em tijolinhos tem o sabor adocicado, mas não é macio ou flexível.

3- Açúcar não refinado, sob a forma de pequenos blocos, tem o sabor agradável do mel, porém não muda de forma quando pressionado.

4- O açúcar, quando ainda não submetido à refinação e, apresentando-se em blocos sólidos de pequenas dimensões e forma tronco-piramidal, tem sabor deleitável da secreção alimentar das abelhas; todavia não muda suas proporções quando sujeito à compressão.

4 Disponível em: https://www.recantodasletras.com.br/artigos/631597. Acesso em: 10 jul. 2018. 
5- A sacarose extraída da cana-de-açúcar, que ainda não tenha passado pelo processo de purifıcação e refino, apresentando-se sob a forma de pequenos sólidos tronco-piramidais de base retangular, impressiona agradavelmente o paladar, lembrando a sensação provocada pela mesma sacarose produzida pelas abelhas em um peculiar líquido espesso e nutritivo. Entretanto, não altera suas dimensões lineares ou suas proporções quando submetida a uma tensão axial em consequência da aplicação de compressões equivalentes e opostas.

6- O dissacarídeo de fórmula $\mathrm{C} 12 \mathrm{H} 22 \mathrm{O} 11$, obtido através da fervura e da evaporação de $\mathrm{H}_{2} \mathrm{O}$ do líquido resultante da prensagem do caule da gramínea Saccharus officinarum, (Lineu, 1758) isento de qualquer outro tipo de processamento suplementar que elimine suas impurezas, quando apresentado sob a forma geométrica de sólidos de reduzidas dimensões e restas retilíneas, configurando pirâmides truncadas de base oblonga e pequena altura, uma vez submetido a um toque no órgão do paladar de quem se disponha a um teste organoléptico, impressiona favoravelmente as papilas gustativas, sugerindo impressão sensorial equivalente provocada pelo mesmo dissacarídeo em estado bruto, que ocorre no líquido nutritivo da alta viscosidade, produzindo nos órgãos especiais existentes na Apismelífera (Lineu, 1758). No entanto, é possível comprovar experimentalmente que esse dissacarídeo, no estado físico-químico descrito e apresentado sob aquela forma geométrica, apresenta considerável resistência a modificar apreciavelmente suas dimensões quando submetido a tensões mecânicas de compressão ao longo do seu eixo em consequência da pequena capacidade de deformação que lhe é peculiar.

Na progressiva transformação e ampliação de conhecimentos sobre a sacarose (itens 1 a 5, acima), destacamos a diferença de um falar coloquial no início para falas que vão se tornando cada vez mais cientificamente elaboradas, instituindo-se como linguagem social da Química. Conforme Sardá e Sanmarti (2003), aprender a construir ideias científicas é uma tarefa que só é possível quando conseguimos expressar o conhecimento utilizando diferentes formas de escrever e falar.

\section{A discursividade que constitui espaços educativos}

Smolka (2010), em estudo que discute as relações de ensino na escola, destaca as relações entre significar e ensinar e afırma que, na construção histórica da sociedade, aprendemos a privilegiar a constância, a unicidade, a homogeneidade, a exatidão, a completude. A autora destaca esses parâmetros como o que define a norma, o normativo, a normalidade, enfatizando que aquilo que não coincide, o que desregula, tem um valor marginal, desviante, anormal, patológico.

Que alternativas pedagógicas respondem a uma educação crítica na formação das crianças, dos jovens? Prática educativa é prática social e política; movimenta-se na realidade e com a realidade, na vida. Como trabalhar a realidade social concreta dos integrantes da comunidade escolar? E como os conhecimentos aparecem, se mostram? (GOULART, 2014). 
Atividades planejadas pelos professores, por professores e alunos, por alunos, por demandas situadas e por demandas espontâneas, inusitadas, muitas vezes expressamse por meio de textos, no contexto de práticas escolares e de práticas vividas, de alguma forma. Temos como pressuposto o fato de que estar na escola envolve conhecer diferentes dimensões da produção do discurso verbal e de outras formas de expressão para que os sujeitos aprendizes se confirmem socialmente como pessoas capazes de refletir e criar e não de repetir e reproduzir, ainda que isso possa acontecer, especialmente em algumas situações sociais e com alguns gêneros.

Os métodos de ensino, neste sentido, fazem grande diferença na constituição de subjetividades, já que neles se estabelecem relações de poder - quem pode e quem sabe falar, ler e escrever na escola? Quem ocupa o lugar de enunciador? O que as atividades propostas às crianças, jovens e adultos fortalecem? Quem propõe, como propõe, por que e para que propõe? Conceber o discurso escrito legitimado socialmente como ponto de partida e de chegada para o processo de alfabetização nos direciona para um conjunto de conhecimentos.

O texto é a unidade de sentido básica do trabalho pedagógico. Por sua concretude social e histórica, as conversas entre crianças e professores são geradoras das primeiras fornadas de textos a povoar a sala de aula. Neste importante movimento discursivo oral, textos escritos de variados gêneros vão sendo significados, por meio de falas em que se discutem compreensões, se comparam ideias e posições, se estabelecem relações com outros textos e situações.

E neste movimento, como em todos os outros, se fazem escolhas sobre o que dizer e como dizer. Os processos que crianças e jovens vivem para compreender como se organiza e se realiza a linguagem escrita, seja de que área for, tanto do ponto de vista formal quanto de sua dimensão político-social, envolvem uma grande complexidade de conhecimentos, especialmente se considerarmos a fase inicial de sua apropriação na perspectiva da produção do discurso escrito por escrito, mas não somente. Na dinâmica da sala de aula, as crianças e os jovens se sentindo confirmados como pessoas, afırmamse, dizendo as suas palavras, falando sobre o que sabem, evidenciam os gêneros do discurso que conhecem, se abrindo para novas apropriações. Com boas intervenções de professores e de colegas de classe, vão ampliando conhecimentos e ao mesmo tempo aprendendo nas formas de conhecer e criar o mundo (GOULART et al., 2005).

O conhecimento é aprendido em contexto enunciativo não se constituindo numa moldura para o ensino. O trabalho educativo se concretiza no horizonte de diferentes linguagens/ conhecimentos sociais, logo também no horizonte da cultura escrita, com seus produtos e práticas. Retirar a cultura escrita do cotidiano de crianças pequenas é sonegar informações que são fundamentais para a compreensão da vida e das possibilidades de vida na sociedade letrada, e também para a compreensão do valor social do sistema alfabético de escrita: o que podemos fazer com ele e o que ele pode fazer conosco. 
Uma escola preocupada com o pragmatismo de resultados imediatos nega os processos de aprendizagem dos sujeitos, suas histórias e experiências. Deixa de perceber a inteligência das pessoas e seus pensamentos complexos. No processo de viver e aprender, as crianças articulam a imaginação; a realidade; a casa; a escola; a rua; o medo; a coragem, com os conhecimentos, transitando livremente entre saberes, sentimentos e sensações.

Considerando a importância do desafio à criação e à aprendizagem crítica, as práticas pedagógicas alfabetizadoras devem abrir janelas para argumentos e pensamentos de todos os tipos, especialmente para aqueles ligados à proposta de atividades em que os alunos possam viver experiências de conhecer a escrita como uma nova linguagem, refletir sobre ela e reinventá-la. Podemos conceber as salas de aula como espaços que se caracterizem por procedimentos em que professores e alunos jamais parem de buscar novas formas de conhecimento e ação.

A aprendizagem da leitura e da escrita a partir e com base em textos se fortalece com a possibilidade de os alunos mergulharem nos sentidos dos textos que leem e inventarem novos sentidos para os textos que escrevem, por meio de atividades heurísticas, como movimentos intelectuais para lidar com as demandas que as situações objetivas de aprendizagem implicam.

\section{Cena familiar 1}

Cecília veio da cozinha com a mãozinha fechada.

- Olha, pai.

Abriu a mão e mostrou alguns milhos apertadinhos.

- O que é isso, filha?

- Semente.

- Ah é? Semente de quê?

- Semente de pipoca.

(Cecília, 2 anos)

\section{Cena familiar 2}

Eu e minha sobrinha brincávamos de mamãe e filhinha. Ela, a mamãe, se propôs a fazer um mingau:

- A mamãe vai fazer um mingau pra você.

- Mingau de quê?

- De aveia.

E, baixando o tom de voz, falou: 
- Mas aveia de mentirinha, tá?

Baixando o tom, do mesmo modo, perguntei:

- Por quê?

- Ué, porque aveia de verdade a gente não come.

- Ué, por que não?

E ela, mostrando o pulso:

- "Aveia" de verdade não é de comer, tem sangue.

(Vallentina, 4 anos)

A proposta que se esboça aqui se liga ao direito à vida, o direito ao conhecimento associado à formação cidadã. 0 direito de reagir, criticar, propor e sugerir. Uma proposta é um caminho, não é um lugar, se faz na história e com a história, já disse alguém. Surge de perguntas e gera novas perguntas. Envolve necessidades, desejos, valores. E demanda uma vontade política coletiva.

Definir princípios teóricos para orientar práticas escolares implica selecioná-los com base em valores humanos, sociais, políticos. Para Saviani (2003), modelos teóricos de campos de conhecimento se produzem na tensão do processo e da prática políticosocial: prática educativa como modalidade específica da prática social, relacionada à concepção de sujeito, a teorias de conhecimento e a projetos de sociedade. Ponto de partida politicamente significativo para refletirmos sobre os processos de alfabetização e de escolarização, de um modo geral.

A dimensão discursiva compreende relações com as experiências de vida dos sujeitos, com seus valores. No processo de ensino-aprendizagem de novas possibilidades de leitura do mundo ficam as cicatrizes das fronteiras da palavra do outro, seus vestígios podem aparecer mesmo na estrutura sintática.

Seguindo a perspectiva indicada por Ponzio (2012) para a análise dos discursos e dos textos, é importante nas experiências pedagógicas de sala de aula, ou relativas a ela, explorar a análise dos discursos, mas também a dialética e a dialógica, para colher a dialogicidade específica de cada discurso. Neste movimento, conhecemos melhor nossos alunos e abrimos espaços para que eles também se conheçam e ampliem seus conhecimentos.

Os processos de ensino necessitam de amplos espaços dialógicos e dialogizados para que argumentos de vários tipos possam florescer, como: o indutivo, do tipo simbólico, que se baseia em hábitos, não havendo relação de constrição entre premissa e conclusão, e caracterizando-se por repetição e identidade; o dedutivo, do tipo indicial, em que a 
conclusão deriva das premissas; e o abdutivo, do tipo icônico, altamente dialógico, implicando amplo espaço para invenção e grande margem de erro (GOULART, 2014).

Ligados à proposta de atividades em que os alunos possam viver experiências de conhecer a escrita como uma nova linguagem, refletir sobre ela e reinventá-la, podemos conceber as salas de aula como espaços que se caracterizem por procedimentos heurísticos, em que professores e alunos jamais parem de buscar novas formas de conhecimento e ação. Pode-se pensar a escola com uma lógica interna própria, institucionalmente falando; e pensar a escola com uma lógica externa, elaborada histórico-socialmente, em movimento. O desafio é definir princípios pedagógicos em que as janelas das salas de aula permaneçam abertas para a sociedade, para o mundo, colocando sempre o presente numa situação crítica, como nos indica Konder (1988).

A concepção de práticas pedagógicas em que os alunos, os professores e os conhecimentos sejam as molas propulsoras dos processos de aprender-ensinar, em vez de métodos e instruções, deve prevalecer. Os processos humanos apresentam regularidades mecânicas ao lado de criações imprevistas, imperfeições, incertezas, sustos. Na escola os processos também devem ser pensados assim. Além disso, os conhecimentos e seus modos de organização são objeto da cultura e não da escola.

A dimensão discursiva dos processos de ensino e de aprendizagem compreende relações com as experiências de vida dos sujeitos, com seus valores. Não basta providenciar um contexto para as unidades de trabalho, textos, conceitos ou categorias. O discurso é concebido como o ponto de partida teórico-metodológico para conceber modos de ensinar.

Ao final de um projeto pedagógico sobre polvos, crianças de 7 anos escreveram textos, apresentando o que haviam aprendido sobre o animal. Abaixo, está o texto de um menino que ilustra a nossa explanação ao colocar em destaque o polvo gigante que chamou muita atenção das crianças, a considerar o número de alunos que o colocou como foco temático.

Texto: O polvo gigante/Ele é muito brincalhão e inteligente, ele tem 8 pernas./É ovíparo e fica botando ovo de 30.000 a 100.000 e depois morre/Ele só tem 8 pernas e 1 cabeça, o polvo maior tem/9 metros, o filhote nasce de 6 milímetros, o maior/tem 2.000 ventosas./Eles para esconder eles esconder na pedra./Eles comem siri e camarão, eles também mudam de cores de acordo com o lugar. 


\section{Utolnod axpentes}

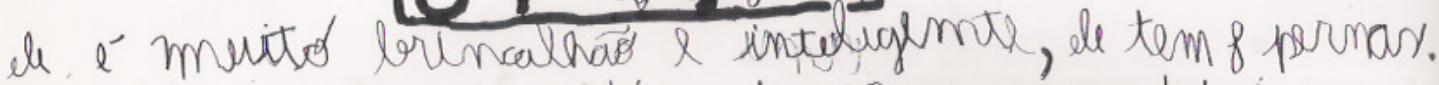

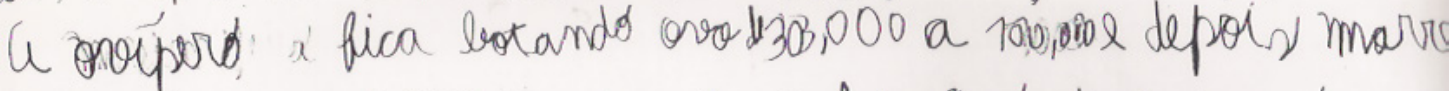
el só tem \& pernaril \& 1 cabrses of paroo maios ten

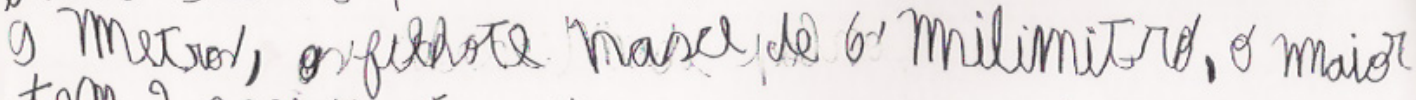
term 2,0000 cemtosar. eles para cercomder eles esconder ha pedica.

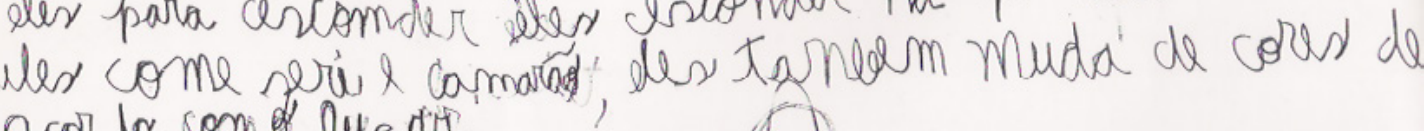
acordos consel luegatr.

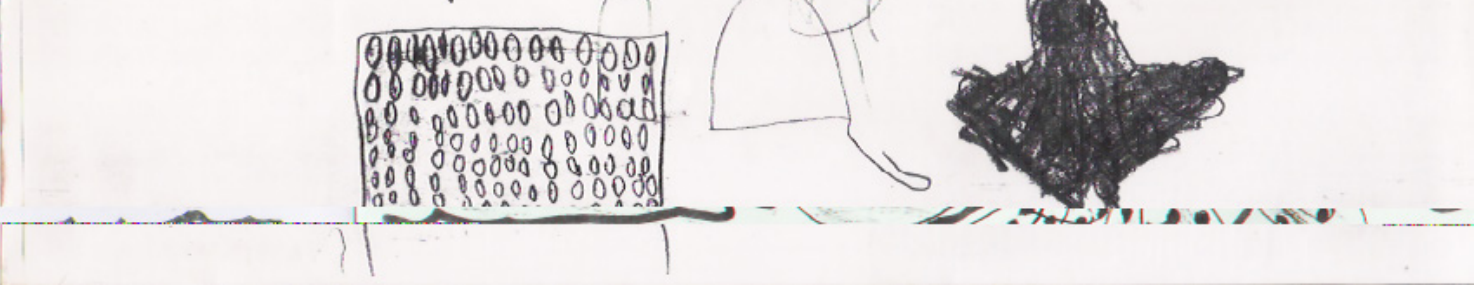

O que se destaca no texto da criança em relação à linguagem social em foco? 0 esforço para elaborar o texto com cunho científico, em que a objetividade chama atenção, em marcas características do discurso da ciência. A partir do título o polvo gigante, a criança faz características do animal sobressaírem: modo de reprodução; alimentação; adaptação ao meio/mecanismos de defesa; e outras ainda, ligadas a destaques de aspectos do polvo, animizando-os - "ele é muito brincalhão e inteligente".

Como os sujeitos dão sentido ao que aprendem (GOULART, 2005, 2007, 2009, 2010)? Como ensinar a eles?

A cultura e a história são inerentes à concepção de enunciado/discurso de Bakhtin, não como categorias singulares e estáticas, mas como atravessamentos dinâmicos movimentando de variados modos as relações dos sujeitos, suas vidas, suas histórias. Nas relações, o outro tem papel formativo. Suas expressões manifestam de muitos modos suas origens, valores, verdades. Com a linguagem, pelo seu caráter de regulação, constituem-se modos de apreensão de sentidos, e pelo seu caráter de indeterminação, se constituem as possibilidades de transformação de sentidos. Estes são espaços de elaboração e reelaboração de conhecimentos. Tornam-se abertos no convívio de troca em que tanto a causalidade quanto a casualidade que cercam a nossa existência encontrem terreno fértil para se apresentarem em nossos discursos, em que uma razão dialógica prevaleça. 
Quem realmente parte da vida das crianças de camadas populares, de sua percepção das coisas, dos objetos, dos fatos, permite que essa percepção sentida, vivida, venha para a sala de aula e assume os riscos de conviver com o que não é aceito, não é legítimo. Situa-se no espaço do confronto, ensina pela linguagem das vivências e chega à leitura dessas linguagens. Não constrói outras teorias sobre uma prática, que, por si, já pressupõe uma posição teórica, não formula exercícios sobre uma realidade de vida para preparar para a vida [...] (MOYSÉS, 1985, p. 89).

Em que práticas de linguagem os alunos estão aprendendo sobre o mundo, sobre as relações entre os sujeitos, sobre o ser humano, sobre a sociedade? De que conhecimentos se apropriam por meio dessas práticas? Transformam seus modos de ser e viver?

Rocha (2006, p. 394) observa em sua tese a dificuldade de alunos de $7^{\text {a }}$ série lidarem com textos, principalmente de livros didáticos de História, que "requerem o domínio de um léxico, que não chega à formalização das fórmulas ou de vocábulos como o de taxionomias da Biologia, mas que são referentes a determinadas cronotopias, como por exemplo, à Antiguidade, ou à Revolução Industrial". Com base no pequeno texto abaixo, uma das questões solicitadas pela professora foi como os meninos gregos estudavam. Questão problemática para um menino que não conhecia as palavras marcadas com aspas.

Os meninos que iam à escola aprendiam a ler, escrever, fazer contas com o "ábaco" [...]. Mas podiam encontrar um "filósofo" que ensinasse grupos de jovens, ao ar livre, na "ágora" ou no "ginásio".

Tornar permeáveis os textos trabalhados em sala de aula por meio de leituras e conversas se mostra uma necessidade. De acordo com Rocha (2006, p. 394), "é neste lugar que o professor se faz compreender de forma privilegiada, por conta da contextualização face-a-face". A pesquisadora destaca ainda que esse meio também contribui "para a descontextualização controlada através da percepção sensível do professor de suas possibilidades e do uso oportuno da escrita e da busca de sua compreensão" (ROCHA, 2006, p. 399).

A autora destaca enfaticamente a importância da inserção dos alunos na cultura escrita desde os anos iniciais do processo de escolarização como forma de contribuir para que o ensino e a aprendizagem da disciplina História sejam facilitados. Outro alerta importante de Rocha (2006) é sinalizado quando afirma ao final que, ao longo de todo estudo, a complexidade das condições para o ensino na atualidade e a delicadeza do lugar do discurso nas aulas sobressaíram. As práticas escolares, a depender do modo como são desenvolvidas, podem comprometer aspectos pedagógicos importantes, como a 
curiosidade, a explicação, a busca e a criação de conhecimentos, relevantes para que tanto professores quanto alunos renovem sentidos de tempos e espaços, reinventandose.

Para concluir a exposição, trago Smolka (2017) que tem sido uma importante companheira de trabalho, inspiradora e fomentadora da busca de novas formas de pensar a escola para dar conta dos desafios da contemporaneidade. É do denso e perturbador artigo de 2017 que recolhemos duas posições teórico-metodológicas (SMOLKA, 2017) que se coadunam com as reflexões aqui apresentadas. A primeira é a posição de tomar o discurso como eixo do trabalho de ensinar e aprender. Smolka salienta que a dimensão discursiva não desloca e não se descola do aspecto linguístico-cognitivo, mas o permeia e redimensiona. A autora destaca que o ponto de vista "viabiliza a compreensão das infinitas possibilidades e modos singulares de resposta, de apreensão, de apropriação, pelas crianças, das formas de perceber, sentir, falar, ler, escrever, historicamente constituídas; e nessa abertura para as possibilidades de 'novas formações's (VIGOTSKI, 1996), ampliam-se as margens de interpretação das ações e dos gestos das crianças nas relações de ensino."

A segunda é o destaque de Smolka para as salas de aula como espaços de elaboração onde os adultos aprendem (Incansavelmente? - pergunta Smolka.) sobre os modos de aprender das crianças; modos de aprender que são, inescapavelmente, modos de apropriação da cultura. Nesse sentido, o modo de conceber a ontogênese na história e na cultura faz diferença nas relações de ensino. A ontogênese desse modo é o lócus por excelência das (trans)formações históricas: participando ativamente das práticas sociais, apropriandose da cultura, as crianças a (e se) transformam. (SMOLKA, 2017).

Para finalizar, estendemos uma ponte de fértil diálogo entre as posições de Smolka e a nossa defesa de que as salas de aula se abram como espaços discursivamente orientados em que argumentos abdutivos sejam instigados e valorizados, além dos indutivos e dedutivos, tão prestigiados pela escola. São o espaço de invenção e criação e, muitas vezes, do erro, que também pode ser ponte para novas descobertas (GOULART, 2014).

\section{REFERÊNCIAS}

BAKHTIN, M. O homem ao espelho. Apontamentos dos anos 1940. São Carlos: Pedro \& João Editores, 2019.

5 As novas formações, ou seja, as transformações dinâmicas que ocorrem nas formas de atividade mental, no processo de desenvolvimento cultural da criança, dependem da orientação do meio social, isto é, da situação social de desenvolvimento. 
BAKHTIN, M. Problemas da poética de Dostoievski. Tradução Paulo Bezerra. 3. ed. Rio de Janeiro: Forense Universitária, 2005.

BAKHTIN, M. Problemas da Poética de Dostoievski. Tradução Paulo Bezerra. Rio de Janeiro: Forense Universitária, 2002 [Original russo, 1929].

BAKHTIN, M. Questões de literatura e de estética. A teoria do romance. Tradução Aurora Fornoni, José Pereira Jr et alii. 4. ed. São Paulo: UNESP: Hucitec, 1998 [Original russo, 1924].

BAKHTIN, M. (V. N. Voloshinov). Marxismo e filosofia da linguagem. Tradução Michel Lahud e Yara Frateschi Vieira. 4. ed. São Paulo: Hucitec, 1988.

CHARRET, H. da C. Física em verso e prosa: a voz dos alunos sobre a física escolar através de redações. 2009. Dissertação (Mestrado em Educação) - Instituto de Letras, Universidade Federal Fluminense, 2009.

FRANCHI, C. Criatividade e Gramática. Trabalhos em Linguística Aplicada, Campinas: UNICAMP, n. 9, p. 5-45, 1987.

GOULART, C. M. A. Perspectivas de alfabetização: lições da pesquisa e da prática pedagógica. Revista Raido, Dourados: Universidade Federal da Grande Dourados, v. 8, n. 16, p. 157-175, jul./dez. 2014.

GOULART, C. M. A. Alfabetização, discurso científico e argumentação. In: LEITÃO, S.; DAMIANOVIC, M. C. Argumentação na escola: o conhecimento em construção. São Paulo: Pontes, 2011. p. 129-151.

GOULART, C. M. A. Processos escolares de ensino e aprendizagem, argumentação e linguagens sociais. Revista Bakhtiniana, São Paulo, v. 1, n. 4, p. 50-62, 2º sem. 2010.

GOULART, C. M. A. Em busca de balizadores para a análise de interações discursivas com base em Bakhtin. Revista de Educação Pública, Cuiabá: Editora da UFMT, v. 18, n. 36, p. 15-31, jan./abr. 2009.

GOULART, C. M. A. Enunciar e argumentar: analisando um episódio de uma aula de História com base em Bakhtin. Pro-posições, v. 18, n. 3 (54), p. 93-107, set./dez. 2007. 
GOULART, C. M. A. Linguagens sociais e argumentação: investigando modos de letrar e ser letrado. Apresentado no Seminário Dialogismo Bakhtiniano: interlocuções com a linguística, a psicologia e a educação, Curso de Pós-Graduação em Psicologia, Núcleo de Pesquisa em Argumentação, UFPE, junho de 2005.

GOULART, C. M. A. et alii. Processos de letramento na infância: modos de letrar e ser letrado na família e no espaço educativo formal. 2005. Relatório final de pesquisa. Universidade Federal Fluminense, Faculdade de Educação, CNPq, dezembro de 2005.

GOULART, C.; GONTIJO, C. M. M.; FERREIRA, N. S. de A. (org.). A alfabetização como processo discursivo: 30 anos de "A criança na fase inicial da escrita". São Paulo: Cortez, 2017.

INAF Brasil 2018. Indicador de alfabetismo funcional. Principais resultados. Relatório. Instituto Paulo Montenegro; Ação Educativa; IBOPE Inteligência, São Paulo/SP, 2018.

KONDER, L. Walter Benjamin: o marxismo da melancolia. São Paulo: Campus, 1988.

MACHADO, I. A questão espaço-temporal em Bakhtin: cronotopia e exotopia. In: PAULA, L.; STAFUZZA, G. (org.). O círculo de Bakhtin: teoria inclassificável. Campinas: Mercado das Letras, 2010. p. 203-234.

MOYSÉS, S. A. Alfabetização: Estratégia do código ou confronto da história? Educação e Sociedade, São Paulo, n. 22, p. 84-92, set./dez. 1985.

NERUDA, P. Livro das perguntas. Tradução Ferreira Gullar. Ilustração Isidro Ferrer. Rio de Janeiro: Cosac Naify, 2008.

PACHECO, C. M. G. Um estudo exploratório de aspectos do processo de produção de textos escritos por crianças de 7 anos. 1992. Dissertação (Mestrado em Letras) - Pontifícia Universidade Católica, Rio de Janeiro, 1992.

PACHECO, C. M. G. Era uma vez três cabritinhos: a gênese do processo de produção de textos escritos. 1997. Tese (Doutorado em Letras) - Pontifícia Universidade Católica, Rio de Janeiro, 1997.

PONZIO, A. Dialogando sobre diálogo na perspectiva bakhtiniana. São Carlos: Pedro \& João Editores, 2012. 
POSSENTI, S. Enunciação, autoria e Estilo. Revista Brasileira da FAEEBA, Salvador, n. 15, p. 15-21, jan./jun. 2001.

ROCHA, H. A. B. O lugar da linguagem no ensino de história: entre a oralidade e a escrita. 2006. Tese (Doutorado em Educação) - Universidade Federal Fluminense, Niterói, 2006.

RODRIGUES, N. Flor de Obsessão: as 1000 melhores frases de Nelson Rodrigues. Organização e seleção Ruy Castro. São Paulo: Companhia das Letras, 1997.

SALOMÃO, M. M. M. A questão da construção do sentido e a revisão da agenda dos estudos da linguagem. Veredas: Revista de estudos linguísticos, Juiz de Fora, v. 3, n. 1, p. 61-79, 2009.

SANTOS, A. P. Linguagem, gêneros do discurso e práticas pedagógicas: a organização dos textos escritos de alunos dos anos iniciais do ensino fundamental. 2015. Tese (Doutorado em Educação) - Instituto de Letras, Universidade Federal Fluminense, Rio de Janeiro, 2015.

SARDA, A.; SANMARTI, N. Enseñar a argumentar cientificamente. Un reto de las clases de ciencias. Enseñanza de las Ciencias, p. 405-422, 2003.

SAVIANI, D. Pedagogia histórico-crítica: primeiras aproximações. 8. ed. Campinas: Autores Associados, 2003.

SMOLKA, A. L. B. A criança na fase inicial da escrita: a alfabetização como processo discursivo. São Paulo: Cortez; Campinas: Editora da Universidade de Campinas, 1988.

SMOLKA, A. L. B. Da alfabetização como processo discursivo: os espaços de elaboração nas relações de ensino. In: GOULART, C.; GONTIJO, C. M. M.; FERREIRA, N. S. de A. (org.). A alfabetização como processo discursivo: 30 anos de "A criança na fase inicial da escrita". São Paulo: Cortez, 2017. p. 23-46.

SMOLKA, A. L. B. et al. Leitura e desenvolvimento da linguagem. São Paulo: Global; Campinas: ALB - Associação de Leitura do Brasil, 2010.

VIGOTSKI, L. S. Obras escogídas. v. IV. Madrid: Visor, 1996. 